\title{
Gynecomastia as a presenting symptom of Graves' disease in a 49-year-old man
}

\author{
N Mohammadnia, S Simsek and F Stam \\ Department of Internal Medicine, Northwest Clinics, Alkmaar, the Netherlands
}

Correspondence

should be addressed

to N Mohammadnia

Email

n.mohammadnia@nwz.n

\section{Summary}

Gynecomastia is a symptom with a potential high disease burden. It has a variety of underlying causes, such as malignant, drug-related or hormonal. The presence of gynecomastia can be explained in thyrotoxicosis due to a concomitant disbalance of sex hormones. Interestingly, it rarely is the presenting symptom of Graves' disease. A 49-year-old man presented to our outpatient clinic with right-sided gynecomastia. After thorough history taking, more symptoms of thyrotoxicosis were present. Treatment was started with thiamazole and later levothyroxine. Three months after this treatment the gynecomastia and other symptoms resolved completely. A disbalance of sex hormones due to an increased expression of the protein sex hormone-binding globulin (SHBG) caused by thyrotoxicosis could result in gynecomastia. In vitro and in vivo research in mice suggest that the pathophysiology of thyrotoxicosis-associated gynecomastia is due to upregulation of hepatocyte nuclear factor-4 $\alpha(\mathrm{HNF} 4 \mathrm{~A})$ in liver cells. Subsequent increase of SHBG results in a decrease of free testosterone levels.

\section{Learning points:}

- Gynecomastia is a common finding (up to almost 40\%) on physical examination in patients with hyperthyroidism.

- In gynecomastia, thyroid function tests should be examined on initial presentation because of the relative simple treatment.

- The pathophysiology of thyrotoxicosis-associated gynecomastia is well understood by a sex-hormonal disbalance due to an increased expression of SHBG.

- Due to the well explainable pathophysiology, reduction of symptoms can be expected after treatment.

- The underlying mechanism of an increased expression of SHBG is not well understood. However, in vitro and in vivo research in mice suggests that thyrotoxicosis causes an increased expression of HNF4A in liver cells. Thus, upregulating the expression of SHBG.

- Interestingly, HNF4A is suspected to play an important role in MODY. Future research will clarify the importance of this gene and might open up new insights for therapy.

\section{Background}

Asymptomatic gynecomastia has a high prevalence in men (1). Depending on age, the prevalence ranges roughly from 50 to $70 \%$ (1). It has a vast array of possible etiologies, including drug-related, malignant or hormonal causes $(1,2)$. A relative shortage of free testosterone levels in comparison to estrogen levels can result in gynecomastia in male patients (2). This situation occurs in physiologic conditions, for example, before birth, when DHEA converses into estrogens. However, this disbalance can also evolve in pathophysiological states as in thyrotoxicosis. Gynecomastia is a common finding on physical examination in patients with hyperthyroidism, some case-series describe a prevalence of almost $40 \%$ (3). Interestingly, it rarely is the presenting symptom of 
primary hyperthyroidism. We present a case of Graves' disease-associated gynecomastia. The pathophysiology will be reviewed, including some current insights. Recently the European Academy of Andrology published a guideline on the management of gynecomastia, where measurement of thyroid hormones is also recommended in the evaluation of gynecomastia (4). Gynecomastia has a potential major mental impact on patients (5). Moreover, thyrotoxicosis associated sexual dysfunction contributes to disease burden, and can also be the presenting symptom of thyroid disease (6). Early recognition of hyperthyroidism as a cause of gynecomastia can speed up the diagnostic process and treatment, and decrease disease burden.

\section{Case presentation}

A 49-year-old man, consulted his general practitioner with an increase of his breast size on the right side over the last 3 months. Initially, a mammography was conducted that showed gynecomastia without signs of a malignancy. The patient did not use any medication. Subsequently, the patient was referred to the outpatient clinic of our internal medicine department. History taking revealed weight loss of $6 \mathrm{~kg}$, decreased exercise tolerance and loss of libido. In addition, the patient also suffered from tachycardia, moist hand palms and a fine tremor. The patient did not have a history of other auto-immune diseases, such as type 1 diabetes mellitus, celiac disease or vitiligo. The family history was positive for thyroid disease.

\section{Investigation}

Physical examination showed a healthy-appearing man with a fine tremor. The BMI was $23.0 \mathrm{~kg} / \mathrm{m}^{2}$, pulse rate 67 beats per minute, blood pressure $146 / 83 \mathrm{mmHg}$ and temperature $38.0^{\circ} \mathrm{C}$. The thyroid gland was slightly enlarged, without tenderness or palpable nodules. Breast examination showed a bilateral increased volume of the mammary gland (most prominent on the right side), with a more firm consistency than the surrounding adipose tissue, corresponding to gynecomastia Tanner scale M2. The testicles had a normal size and consistency, no palpable abnormalities were found. Laboratory tests showed suppressed thyroid-stimulating hormone (TSH) levels of $<0.02 \mathrm{mU} / \mathrm{L}$ (normal range: $0.3-5.6 \mathrm{mU} / \mathrm{L}$ ) and elevated FT4 of $20.5 \mathrm{pmol} / \mathrm{L}$ (normal range: 7.0-16.0 $\mathrm{pmol} / \mathrm{L})$. Anti-TSH receptor antibodies values were 8.3 IU/L (normal range: 0.0-3.3 IU/L). The circulating level of sex hormone-binding globulin (SHBG) was elevated with $143 \mathrm{nmol} / \mathrm{L}$ (normal range: 18-54 nmol/L) with a normal plasma testosterone, but decreased free calculated testosterone level of $0.12 \mathrm{nmol} / \mathrm{L}$ (normal range: 0.15--0.60 $\mathrm{nmol} / \mathrm{L}$, calculated with the Vermeulen equation) and a normal estradiol level. Testosterone and estradiol levels are determined by immunoassay in our laboratory. Levels of prolactin and human chorionic gonadotropin were normal. The diagnosis of Graves' disease was made, explaining both the hyperthyroidism and the gynecomastia.

\section{Treatment}

After diagnosis, treatment was started with thiamazole 30 milligrams once daily. After 1 month, levothyroxine was added in an incremental dose up to $100 \mu \mathrm{g}$ once daily (block and replace regimen).

\section{Outcome and follow-up}

The monthly follow-up laboratory findings are shown in Fig. 1 and Table 1. Free T4 and T3 levels decreased to normal range within 1 month of treatment and TSH levels remained low. SHBG levels decreased significantly after 2 months and the calculated free testosterone increased to normal range values. The general well-being improved gradually from the start of treatment, and after 3 months the gynecomastia had resolved and libido was restored to the premorbid level.

\section{Discussion}

Two different mechanisms contribute to the development of gynecomastia in thyrotoxicosis (shown in Fig. 2). The first and major contributing factor to this disbalance is a thyroid hormone-induced increased production of the plasma protein SHBG in the liver. Only a small fraction

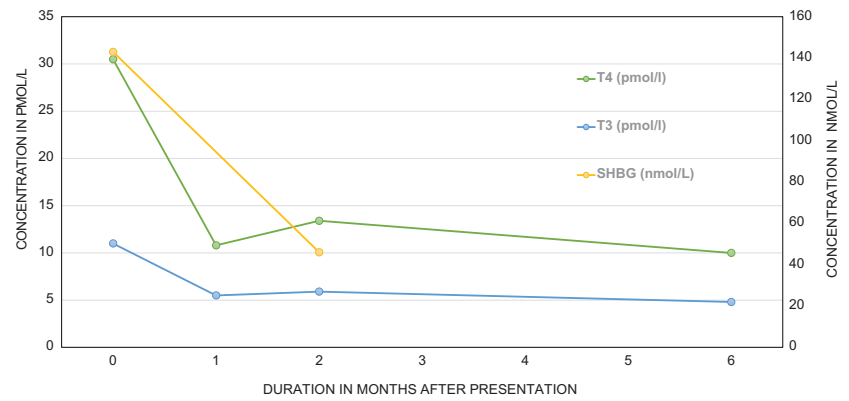

Figure 1

Free thyroxine (T4) and triiodotyronine (T3) levels in comparison to sex hormone-binding globulin (SHBG) over time. 
Table 1 Laboratory findings of patient over time.

\begin{tabular}{l}
\hline \\
\hline Free T4 (pmol/L) \\
Free T3 (pmol/L) \\
TSH $(\mathrm{mU} / \mathrm{L})$ \\
$\mathrm{LH}(\mathrm{U} / \mathrm{L})$ \\
FSH $(\mathrm{U} / \mathrm{L})$ \\
Anti-TSH receptor $(\mathrm{IU} / \mathrm{L})$ \\
SHBG $(\mathrm{nmol} / \mathrm{L})$ \\
Testosterone $(\mathrm{nmol} / \mathrm{L})^{\star}$ \\
Free testosterone $(\mathrm{nmol} / \mathrm{L}) \star *$ \\
Estradiol (nmol/L)* \\
Alpha-fetoprotein $(\mu \mathrm{g} / \mathrm{L})$ \\
Prolactin $(\mathrm{IU} / \mathrm{L})$ \\
Creatinine $(\mu \mathrm{mol} / \mathrm{L})$ \\
ASAT $(\mathrm{U} / \mathrm{L})$ \\
ALAT $(\mathrm{U} / \mathrm{L})$ \\
Alkaline phosphatase $(\mathrm{U} / \mathrm{L})$ \\
Gamma-glutamyl transferase $(\mathrm{U} / \mathrm{L})$ \\
Medication \\
$\quad$ Thiamazole \\
Levothyroxine
\end{tabular}

\begin{tabular}{c}
\hline Reference range \\
\hline $7.0-16.0$ \\
$4.1-6.4$ \\
$0.3-5.6$ \\
$1.20-8.60$ \\
$1.30-11.00$ \\
$0.0-3.3$ \\
$20.6-76.6$ \\
$7.5-27.0$ \\
$0.15-0.60$ \\
$<0.18$ \\
$0-9$ \\
$0-0.30$ \\
$60-110$ \\
$0-35$ \\
$0-45$ \\
$0-120$ \\
$0-55$ \\
\end{tabular}

\begin{tabular}{c}
\hline Start thiamazole \\
\hline 30.5 \\
11.0 \\
$<0.02$ \\
2.40 \\
5.70 \\
8.3 \\
143 \\
18.5 \\
0.12 \\
0.14 \\
- \\
0.21 \\
82 \\
25 \\
45 \\
104 \\
16
\end{tabular}

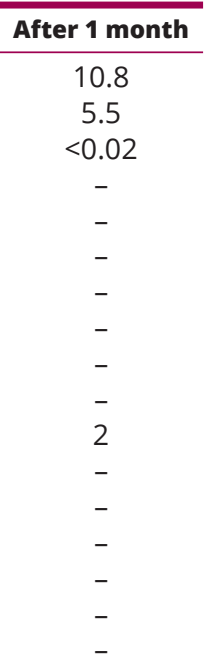

\begin{tabular}{c}
\hline After $\mathbf{2}$ months \\
\hline 13.4 \\
5.9 \\
$<0.02$ \\
-
\end{tabular}

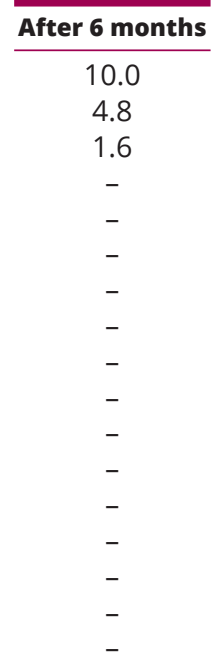

$30 \mathrm{mg}$
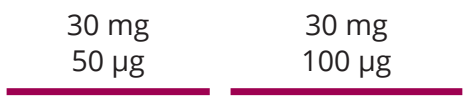

$30 \mathrm{mg}$ $100 \mu \mathrm{g}$

*Testosterone and estradiol levels were determined by immunoassay. **Free testosterone levels were calculated using the Vermeulen equation.

$(1-3 \%)$ of the total testosterone levels circulates freely in the body, thus being biochemically active (7). The majority is bound to plasma proteins, especially albumin and SHBG (7). SHBG plays an important role in the development of

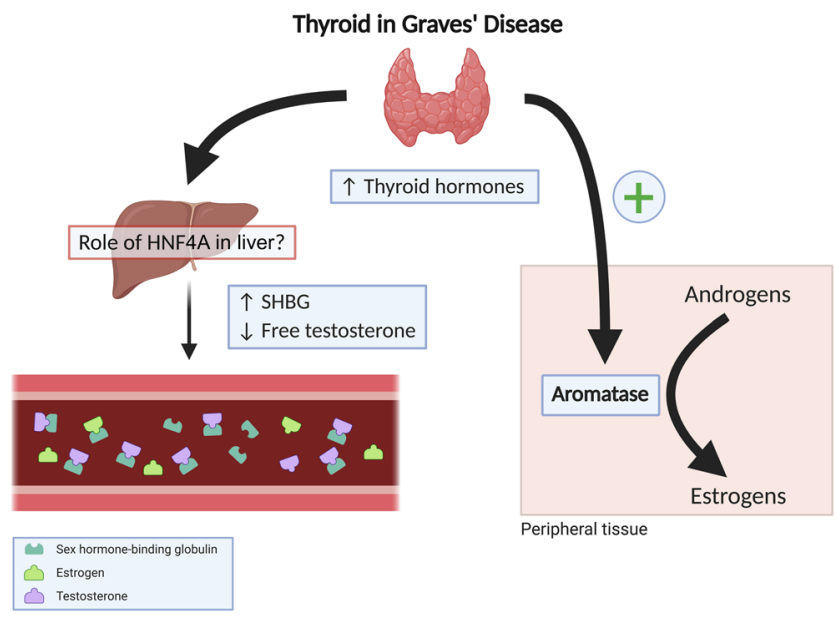

Figure 2

Underlying mechanisms of gynecomastia in Graves' disease. The figure shows how thyrotoxicosis results in hormonal disbalance, and thus gynecomastia. The left pathway shows that increased production of thyroid hormones due to Graves' disease stimulate the liver into an increased expression of SHBG. HNF4A is suspected to play an important role as the underlying mechanism of the upregulation of SHBG. SHBG binds free testosterone more than estrogen, thus creating a relative low testosterone level in comparison to the pre-morbid state. The right pathway illustrates that thyroid hormones stimulate the activity of aromatase in peripheral tissue, thus decreasing the total amount of androgens in the body. gynecomastia in thyrotoxicosis by regulating the plasma levels of sex hormones $(2,7,8)$. It binds both testosterone as estrogen, but the binding affinity for androgens is much higher (7). SHBG is regulated by a widespread variety of factors, including different inflammatory cytokines and diet (9). In vitro research of human hepatoblastoma cell lines (HepG2) showed an increase in SHBG production after stimulation with thyroid hormones $(8,10)$. The exact pathway behind thyroid hormone increased SHBG levels remains unclear, but hepatocyte nuclear factor- $4 \alpha$ (HNF4A) seems to play an essential role $(9,11)$. HNF4A is a protein and transcription factor, expressed by the HNF4A gene that regulates several proteins as SHBG, found in cells in the liver. It binds to a specific part in the SHBG promotor region, thus regulating the expression of this gene (11). In vitro research showed that stimulation of HepG2 cells with thyroid hormones increased SHBG levels after 2 days, commensurate with higher intracellular HNF4A levels (11). Moreover, in vivo research in mice showed an increased expression of HNF4A in liver cells and SHBG levels after administration of thyroid hormones (11). The exact mechanism on how thyroid hormones increase HNF4A levels is not well understood, but the effects of thyroid hormones on basal metabolic states in cells are suspected to play an important role (11). Interestingly, this gene also seems to play an important role in diabetes and specifically in maturity-onset diabetes of the young (MODY) in pancreatic $\beta$-cells (12). Moreover, insulin resistance seems to be correlated to lower SHBG 
gene expression in adults (13). These findings portray that SHBG is also involved in other metabolic processes besides thyrotoxicosis. Future research needs to determine the specific role of this molecule and whether it could be a novel insight for therapies. SHBG concentrations can be measured in the serum directly to evaluate the circulating levels as was conducted in our case.

The second underlying pathophysiological cause is due to an increased activity of aromatase by thyroid hormones, that converts androgens into estrogens in peripheral tissue $(1,7)$. Thus, dysregulating the hormonal balance by increasing estrogen levels. As discussed before, the SHBG concentration decreased after start of treatment, normalizing the homeostasis of the sex hormones to premorbid state. In correlation with the laboratory results, the gynecomastia also disappeared, substantiating the aforementioned pathogenesis of thyrotoxicosis-associated gynecomastia.

\section{Declaration of interest}

The authors declare that there is no conflict of interest that could be perceived as prejudicing the impartiality of the research reported.

\section{Funding}

This research did not receive any specific grant from any funding agency in the public, commercial or not-for-profit sector.

\section{Patient consent}

Written informed consent was obtained from the patient for this case report.

\section{Author contribution statement}

F S proposed the original idea for this case report. $\mathrm{N} \mathrm{M}$ drafted the manuscript. F S and S S critically reviewed the manuscript. N M revised the manuscript into its final version.

\section{Acknowledgements}

Figure 2 was created using BioRender.com software.

\section{References}

1 Johnson RE \& Murad MH. Gynecomastia: pathophysiology, evaluation, and management. Mayo Clinic Proceedings 200984 1010-1015. (https://doi.org/10.1016/S0025-6196(11)60671-X)

2 Braunstein GD. Clinical practice. Gynecomastia. New England Journal of Medicine 2007357 1229-1237. (https://doi.org/10.1056/ NEJMcp070677)

3 Ashkar FS, Smoak 3rd WM, Gilson AJ \& Miller R. Gynecomastia and mastoplasia in Graves' disease. Metabolism: Clinical and Experimental 197019 946-951. (https://doi.org/10.1016/00260495(70)90041-7)

4 Kanakis GA, Nordkap L, Bang AK, Calogero AE, Bártfai G, Corona G, Forti G, Toppari J, Goulis DG \& Jørgensen N. EAA clinical practice guidelines - gynecomastia evaluation and management. Andrology 20197 778-793. (https://doi.org/10.1111/andr.12636)

5 Kipling M, Ralph JE \& Callanan K. Psychological impact of male breast disorders: literature review and survey results. Breast Care 2014 9 29-33. (https://doi.org/10.1159/000358751)

6 Gabrielson AT, Sartor RA \& Hellstrom WJG. The impact of thyroid disease on sexual dysfunction in men and women. Sexual Medicine Reviews 20197 57-70. (https://doi.org/10.1016/j.sxmr.2018.05.002)

7 Anderson DC. Sex-hormone-binding globulin. Clinical Endocrinology 19743 69-96. (https://doi.org/10.1111/j.1365-2265.1974. tb03298.x)

8 Rosner W, Aden DP \& Khan MS. Hormonal influences on the secretion of steroid-binding proteins by a human hepatoma-derived cell line. Journal of Clinical Endocrinology and Metabolism 198459 806-808. (https://doi.org/10.1210/jcem-59-4-806)

9 Simo R, Saez-Lopez C, Barbosa-Desongles A, Hernandez C \& Selva DM. Novel insights in SHBG regulation and clinical implications. Trends in Endocrinology and Metabolism 201526 376-383. (https://doi.org/10.1016/j.tem.2015.05.001)

10 Raggatt LE, Blok RB, Hamblin PS \& Barlow JW. Effects of thyroid hormone on sex hormone-binding globulin gene expression in human cells. Journal of Clinical Endocrinology and Metabolism 199275 116-120. (https://doi.org/10.1210/jcem.75.1.1618999)

11 Selva DM \& Hammond GL. Thyroid hormones act indirectly to increase sex hormone-binding globulin production by liver via hepatocyte nuclear factor-4 $\alpha$. Journal of Molecular Endocrinology 2009 43 19-27. (https://doi.org/10.1677/JME-09-0025)

12 Yamagata K. Roles of HNF1 $\alpha$ and HNF $4 \alpha$ in pancreatic $\beta$-cells: lessons from a monogenic form of diabetes (MODY). Vitamins and Hormones 201495 407-423. (https://doi.org/10.1016/B978-0-12-8001745.00016-8)

13 Winters SJ, Gogineni J, Karegar M, Scoggins C, Wunderlich CA, Baumgartner R \& Ghooray DT. Sex hormone-binding globulin gene expression and insulin resistance. Journal of Clinical Endocrinology and Metabolism 201499 E2780-E2788. (https://doi.org/10.1210/jc.20142640)

Received in final form 22 February 2021 Accepted 29 March 2021 